\title{
Integrating Media Clusters and Value Networks: Insights for Management Theory and Research from a Case Study of Mediapolis in Finland
}

\author{
Sari Virta \\ (corresponding author) \\ $\mathrm{PhD}$ Candidate \\ School of Communication, Media and Theatre, University of Tampere, Finland \\ Media Management and Transformation Center \\ Jönköping International Business School, Jönköping University, Sweden \\ sari.virta@ju.se \\ Anfallintie 24B, 02920 Espoo, Finland \\ $+358400656376$

\section{Gregory Ferrell Lowe} \\ Professor \\ School of Communication, Media and Theatre \\ University of Tampere, Finland \\ glowe@pp.inet.fi \\ Kalevantie 4, 33014 Tampereen yliopisto, Finland \\ +358400475300
}

\section{Acknowledgements}

The authors wish to thank Dr. Charmine Härtel for her valuable feedback, comments and suggestions on the earlier versions of the manuscript.

We also wish to acknowledge the helpful comments of the anonymous reviewers.

\section{Financial Support}

This work was supported by the Media Industry Research Foundation of Finland by a grant (no. 201510113) for Sari Virta.

\section{Conflicts of Interest}

None

This manuscript is an original work that has not been submitted to nor published anywhere else. 


\title{
Integrating Media Clusters and Value Networks: Insights for Management Theory and Research from a Case Study of Mediapolis in Finland
}

\author{
Word Count: 9771
}

\begin{abstract}
:
We argue that there is scholarly potential in linking theory on industry clusters with theory on value networks. To date, these two theoretical streams have developed largely in parallel, limiting understanding of how the two are integrated in practice. By considering these theories in combination and the unique context of creative industries, we generate insight on the management of clusters as value networks. Our ongoing longitudinal empirical case is a new media cluster called "Mediapolis" in the city of Tampere, Finland. The case study commenced at the time the cluster was in the planning and early operational stage. Results demonstrate the usefulness of linking the two theories, and support a future research agenda examining the types of cluster configurations meeting the criteria of value networks, and the conditions under which value network cluster configurations are more sustainable than simply a spatial agglomeration of clusters.
\end{abstract}

Keywords: Cluster configurations, creative industries, innovation management, management paradoxes, media management, regional economic development, value networks

\section{INTRODUCTION}

Managers in most industries are coping with rapid change (Ghezzi, 2013) and environmental complexity (Allee, 2009). Finding the strategic fit between a firm and its markets requires continual adaption to evolving conditions. Transformation is context-driven and keyed to the development of new technologies that open opportunities but also cause instability. Companies seek to lower costs and increase innovation, and thus co-operative arrangements are evident in today's emphasis on industrial clusters and value networks. The respective co-operative focus of urban renewal and regional development often prioritises creative industries (Lowe \& Brown, 2015). 
Allee $(2003,2009)$ understands value networks as purposeful configurations of interdependent relationships between multiple organisations that work collaboratively to generate value, mainly economic, but also less tangible forms such as brand prestige. This is done to the mutual benefit of network members through organisational processes and management practices that are complex and dynamic. It is crucial to manage the network as a whole in order to realise its value potential (Duysters, de Man, \& Wildeman, 1999; see also Ritter, Wilkinson, \& Johnston, 2004).

Karlsson and Picard (2011) define industry clusters as spatial agglomeration of firms in a particular industry, along with important adjacent industries, where firms co-locate to facilitate on-going interaction that is integral to production. In other words, clusters are advantageous geographic concentrations of interconnected companies and institutions (see e.g. Connell, Kriz, \& Thorpe, 2014; Davis, Creutzberg, \& Arthurs, 2009; Díez-Vial, \& Fernández-Olmos, 2013; Porter, 1998, 2000). Industry clusters can share resources that include labour, contract services, information and know-how. Much of this interaction between firms is informal and can be unintentional. In the creative industries, especially, cluster-building has exploded (see e.g. Achtenhagen \& Picard, 2014, Davis et al., 2009, Hitters \& Richards, 2002). This is because competition has gone global, innovation has become a priority, economic resources have become insufficient for most firms to pay for everything, and specialised knowledge has grown but also become fragmented.

Both cluster-building and network development are about producing value, which depends on the quality and quantity of collaboration within (internal) and across (external) organisational boundaries (Lowe \& Yamamoto, 2016). Whereas a cluster must be geographically co-located, a network does not require co-location, and depends primarily on the quality of relationships that comprise its members. However, a cluster that is not internally and externally networked stands little chance of accomplishing its intended purposes. Both phenomena emphasise the importance of collaboration, often in publicprivate partnerships, as being vital for sustaining competitive advantage. This is because companies cannot afford an expanding range of knowledge and skills that are necessary to manage a growing assortment of digital platforms in diverse markets.

Research on clusters and networks has developed largely as two parallel streams, limiting theory development and the possibilities an integrated perspective may hold for enlightening management practice. Given the growth of media convergence brought on by digitalisation (Jenkins, 2008) and contemporary interest in cross-platform (or 360-degree) 
production (Dwyer, 2016), collaboration that produces value in creative industries cannot depend purely on co-location - although that remains important. Networks are equally important, both for the utilisation of "global pipelines" and the benefits of "local buzz", to use Bathelt's (2005) terms.

Our research addresses the gap in theory on industry clusters and value networks. We approach this with a focus on creative industries, because in this context, linking clusters and value networks is important for theory development and management practices due to rapid transformation caused by digitalization. This requires creative organisations to rely on networked collaboration for development and innovation, and makes clustering a typical feature (Davis et al., 2009). We adopt a managerial perspective, which assumes that value production requires both management of business networks and in business networks (Ripollés \& Blesa, 2016; see also Ritter et al., 2004).

The research is pertinent to policy making in Europe (especially but not only) because there is significant interest in the potential for creative industries to revitalise national and regional economies by stimulating innovation. The Horizon 2020 project is a relevant and current example of policy interest. Horizon 2020 is an EU programme that promotes research and innovation, offering in total nearly $€ 80$ billion euros of funding over a seven-year period (from 2014 through 2020), making it the biggest EU research and innovation programme of all times. The European Commission (2016) describes Horizon 2020 as "the financial instrument implementing the Innovation Union, a Europe 2020 flagship initiative aimed at securing Europe's global competitiveness".

Following from the above, the aim of this article is to develop insights for management theory and practice by combining research on industry clusters and value networks in the context of creative industries. We structure the remainder of the article by first clarifying the theoretical framework on clusters and value networks. Next, we describe the empirical case, Mediapolis, the methodology, and analysis strategy. Following this, we present our findings, and finally, we conclude with discussion and suggestions for further research. We approached the empirical analysis by focusing on three interdependent levels of management practice: strategic, tactical and operational (Coughlan et al., 2003), in connection with three dualities that Håkansson and Ford (2002) treated as paradoxes: 1) opportunities and limitations (strategic level), 2) influencing and being influenced (tactical level), and 3) controlling and release (operational level). The results demonstrate the 
usefulness of linking theory on creative clusters and value networks to advance management theory and improve management practice.

\section{CLUSTERS AND VALUE NETWORKS}

As noted, we adopt Karlsson and Picard's (2011) definition in our understanding of clusters in the creative industries, focusing on the media industry. According to these authors, "Media clusters include many small, specialized firms as establishments of large media corporations with a potential to generate external economies of scale. They facilitate a fast spread of new ideas and of creative impulses between the media firms and establishments co-located in the cluster" (Karlsson and Picard, 2011, p. 11). For media especially, one or very few large client-firms typically "anchor" each cluster (Noam, 2009). Most agglomerated firms are small, entrepreneurial companies or self-employed freelancers. Anchor companies are the primary buyers of products produced by firms in media clusters unlike other types where sales are often to the external buyers. The anchors establish the credibility of the cluster and facilitate economic stability (Huggins, 2008). For example, the BBC anchors MediaCity in Salford (UK) and Electronic Arts anchors the video game cluster in Vancouver (Canada).

Companies in any industry co-locate to both benefit from lower transaction costs and enjoy higher potential for innovation in product development. The local cultural milieu is an especially important factor for cluster success in creative industries (Bathelt, 2005; Bathelt, Malmberg, \& Maskell, 2004; Krätke \& Taylor, 2004). Vibrant cosmopolitan environments attract young talent from home and abroad who co-locate to enjoy lifestyle benefits and professional opportunities (Florida, 2012). Clusters thrive on the local buzz, but success also depends on connections with trans-local or global pipelines:

"The effects of local interaction and learning are much stronger and durable if they are constantly supported by feedback and new impulses from outside. The point here is that local interaction of 'buzz' and interaction through global or trans-local 'pipelines' create a dynamic process of knowledge creation which is key to understanding a cluster's continued economic success" (Bathelt, 2005, p. 106).

Such pipelines enable the cluster to monitor international developments, explore opportunities to open new markets, and to develop the cluster as an international brand. 
Moreover, the majority of disruptive innovations originate outside the local environment, and often outside the "home" industry (Drucker, 2007). This explains the simultaneous importance of building value networks to extend collaboration within clusters as communities and beyond the confines of a particular location.

The value network concept is rooted in Porter's (1985) concept of a value chain, an analytical device for assessing a production and distribution process as "a neat sequence of value-enhancing activities" (Pil \& Holweg, 2006, p. 72). There are two relevant weaknesses in applying the value chain concept to collaborative configurations. First, it presumes production and distribution are largely internal to a firm. This is less and less the case for media companies. Commissioning content production from independent producers and outsourcing specialised skills (software coding, as an example) are increasingly common. Second, it encourages a managerial focus on control (Peppard \& Rylander, 2006). Porter's (1985) focus was not on creativity and innovation, but on controlling production processes to ensure both higher degrees of efficiency. i.e. less waste, and more consistent quality, i.e. standardisation at a high level. Developing media products, however, increasingly depends on "co-opetitive" relationships. Co-opetition refers to relationships that are simultaneously competitive and collaborative, and cannot be directly controlled (Bilton, 2007; Doyle, 2013). The value chain concept is still useful for assessing internal processes but not as much for those that rely on external dependencies. Thus, the value network concept is a beneficial supplement to cluster theory because it is not so tightly linked with spatial agglomeration, but it does not rule it out. Accordingly, we believe practical success in media cluster development requires the co-related development of networks to produce shared value.

Christensen (1997) highlighted the potential importance of value networks for established companies because they often struggle to achieve breakthrough innovation. In his view, "the value network in which a firm competes has a profound influence on its ability to marshal and focus the necessary resources and capabilities to overcome the technological and organizational hurdles that impede innovation" (p. 54). This supports De Rose's (1994, p. 16) understanding of a value network as "an interconnecting web of valuecreating and value-adding processes". In this connotation, management practice is about the social production of value in a network economy (Benkler, 2006; Castells, 2010; see also Allee, 2009), which is characterised by "complex and shifting patterns of rivalry and cooperation" (Powell, Koput, \& Smith-Doerr, 1996, p. 122) - typically characterised as coopetition. 
The notion of disruptive innovation was first proposed in research on why many older firms find it difficult to develop game changing products, and on the need for growth that is innovation-driven (see Christensen, Raynor \& McDonald, 2015 for an overview; also Christensen 1997; Christensen, 2006). In media industries, the pivotal disruption that began in the early 1990s and is today the focus of adaptation and change is the transition to digital platforms. This is usefully conceived as digital disruption, which "refers to changes enabled by digital technologies that occur at a pace and magnitude that disrupt established ways of value creation, social interactions, doing business and more generally our thinking" (Riemer \& Johnston, 2013; see also Danneels, 2004). Due to digital disruption, media company strategies increasingly emphasise partnerships, collaboration, alliances, joint ventures, coproduction and networks. This pertains to public and private sectors alike (Lowe, 2016). All of that points to an aggregate level of organisation that is purposeful and clearly important for industry success today (Håkansson \& Ford, 2002). Although a value network is comprised of relationships that cannot be directly controlled, they must be managed. This is challenging because networks are fluid, complex, and multidirectional rather than linear - in short, they are reflexive (Allee, 2000, 2009). Value networks are therefore more volatile and more dynamic than value chains, because they are continually evolving, and devolving. Allee and Taug (2006, p. 570) suggest the value of a network hinges on: 1) its connectivity (who can be reached) and 2) its conductivity (what can be transacted).

In a cluster configuration, the degree of density is a function of the number of colocated firms, while intensity is a function of the frequency and range of interactions among them (Picard, 2008). However, in our view, density is a phenomenon of co-location, while intensity prioritises the scale and scope of purposeful interactions - i.e. the network. Colocation in a cluster can guarantee higher degrees of density, because a clutch of firms is spatially agglomerated. The potential degree of interaction is certainly higher on average than for any individual firm located at some distance from other firms in the industry. But despite higher density, being co-located does not guarantee intensity of interaction. In other words, interaction happens partly as a consequence of density, because interpersonal meetings and activities are inevitable. Being located in the same place naturally facilitates bumping into people from other firms and sharing social spaces, but because much of that is informal, the outcomes are often not relevant for business. Thus, the intensity of interactions is not guaranteed by co-location in a cluster, and neither are actionable results for a firm. Achieving that depends on managing the network; even more, to manage the cluster as a 
value network that is both situated in geographic location and positioned in trans-local configuration. The cluster is 'here'; the network is both here and 'there', but it is not everywhere.

A network structure is comprised of nodes and threads (Peppard \& Rylander, 2006; see also Håkansson \& Ford, 2002). The terminology is rooted in technical networks where each computer in a system is referred to as a "node" and the links between nodes are referred to as "threads". The concept has been applied to social networks as a way to conceptualise relationships. A node in the network can be e.g. an individual or an organisation, depending on the level of analysis. The connection, essentially a relationship, can be assessed as the complexity and thickness of the thread. A thread becomes thicker as interactions and coinvestment increase. As networks collaborate, structural interdependencies become complex. Most managers are accustomed to focusing on the firm, and that continues to be essential, but in a network structure the firm's relative position must also be managed (Håkansson \& Ford, 2002; see also Lee \& Yan, 2014). Mutual adjustment is rarely straightforward due to multiple dependencies. Weakening or severing one relationship can affect other relationships. To illustrate, imagine a media cluster with twenty-five firms that rarely interact. The density is high because there are many nodes, but the intensity is low because the threads are thin. Thus, co-location is not adding much value for each participant in the cluster. In principle, the connectivity is high (who can be reached), but in practice, the conductivity is low (what is transacted). In contrast, a media cluster in which participants routinely collaborate has higher intensity (thicker threads) and better conductivity. This ideal scenario is not likely to happen or persist without management.

Although interdependence is a key feature of value networks, the implications are sometimes under-emphasised. In a network configuration, actions taken or not taken by one node affect other nodes, due to the dynamic nature of networks. It is vital to understand that value creation includes not only partners, but also customers, competitors, suppliers, and regulators. This complexity and lack of amenability to direct control means that managers need to deeply consider how the network co-creates value, how their firm's activities affect the network, and how the network affects the firm.

Managing networks poses distinct challenges, which Håkansson and Ford (2002) treated as three paradoxes. We prefer to conceptualise these as dualities. A paradox is comprised of two things that do not make sense separately but make sense when connected, or the reverse (see e.g. Lewis, 2000; Smith \& Lewis, 2011; for paradoxes in management see 
Clegg, Vieira de Cunha, \& Cunha, 2002; Poole \& van de Ven, 1989). Whereas, a duality is a tension between two contrasting aspects that are conjoined in practice (see e.g. Achtenhagen \& Raviola, 2009; Sutherland \& Smith, 2011).

The first duality is conditional: opportunities and limitations. Each network relationship provides opportunities for interaction and the benefits that can accrue from that, but also creates dependencies that limit a node's scope for unilateral action. The second duality is relational: the network has an influence on each node, and each node can influence the network. Both happen simultaneously in network interactions. The least committed node has a dampening influence on the network as a whole, while the most active can exert decisive influence. The third duality is primarily managerial: the more one node is able to control the network, the less effective the network becomes. For example, companies that succeed in forcing their thinking on the network lessen the probability of anything innovative coming from it. This duality is the closest to a paradox in our view. Taken together, the three dualities are analytically useful for capturing the complexity of value network management. In the analysis that follows later, we connect the three dualities with three levels of integration that equally pertain to each organisation and to any configuration of organisations.

Productivity in collaborative relationships hinges on levels of integration or alignment (Coughlan et al., 2003 following Kanter, 1994). This certainly applies to analyses of cluster dynamics and network management. Three levels out of the original five of Coughlan et al. (2003) are important for our research to date: 1) strategic integration focusing on goals among top leaders in the cluster firms or network nodes, 2) tactical integration focusing on professionals engaged with projects, and 3) operational integration focusing on managing the work. The other two of their levels, interpersonal integration and cultural integration, emerge later in the practice of collaboration due to the time required to build mature relationships and cultivate culture(s) based on those relationships (Kanter, 1994). Because we can only so far investigate the early stage of Mediapolis development, the first three levels of integration are the most relevant for our analysis.

For the analysis, we connect the three dualities with these levels in the following way. The strategic level is about opportunities and limitations that are incumbent with network participation. The tactical level is about relationships that are an influence on every node and can be influenced by each node. The operational level is about managing the 
production of collaborative projects (control) without dampening the network's capacity to produce innovation (release).

We do not imply that integration is absolute, or that the levels are isolated or separate. Instead, our analysis aims to demonstrate how the levels are interconnected in practice. Deciding the degrees of integration is a key managerial task, which is fundamentally, "a process of decision-making among independent organisations involving joint ownership of decisions and collective responsibilities for outcomes" (Coughlan et al., 2003, p. 1248). It is therefore vital that managers of companies in a cluster become adept at developing "purposeful networks where both tangible and intangible value exchanges support the achievement of specific outcomes" (Jörgensen, Bergenhotz, Goduscheit, \& Rasmussen, 2011, p. 428, italics for emphasis added). This goes to the heart of our research interest - the degree to which a cluster, in the context of media in the creative industries, is a purposeful network that produces value.

\section{THE CASE, METHODOLOGY AND ANALYSIS STRATEGY}

Key to the advancement of management and organization theory and practice is careful consideration of context (Härtel, 2014; Härtel \& O'Connor, 2014). Context is an essential consideration in the choice of sample and methodology, and contextualization is a critical aspect of analysis and meaningful interpretation (Härtel, 2014; Härtel \& O’Connor, 2014). The unique features of the creative industries generally, and media industries specifically, provide a valuable context for advancing management and organization theory on networks and paradox management.

Media industries are struggling to cope with the rapid environmental change caused by explosive growth in non-linear, digital platforms (Lowe \& Stavitsky, 2016). This growth has undermined the $20^{\text {th }}$ century mass media system so thoroughly that disruption is the defining feature of networked communications in the $21^{\text {st }}$ century. Media companies must develop new business models, integrate cross-platform publishing, master convergence, and achieve organisational renewal (Küng, Picard, \& Towse, 2008). As discussed, innovation is essential and depends on the vitality of collaboration in clusters and through networks.

Media production is highly collaborative, and media industries therefore tend to feature comparatively higher levels of geographic clustering (Davis et al., 2009). Traditional understandings of cluster development are useful, but insufficient to understand media 
clusters in particular, because they largely produce intangible products - i.e. content and media services (Achtenhagen \& Picard 2014; Davis et al., 2009) that depend in part on global trends in popularity. Also, the objectives for media clusters are more complex than for most industries because there is a high degree of reflexivity in cultural, political and economic aims, i.e. they are highly contextualised (Karlsson \& Picard, 2011). Thus, media clusters and networks offer an especially relevant focus for research on management theory about collaborative arrangements, dynamics and peculiarities. Particularly, when linked with the value network perspective, the potential is higher than usual for fruitful investigation of the interconnectedness of management theory and practice (see Galvin, 2014).

\section{Case description}

Our empirical case is a young media cluster called Mediapolis that is located in Tampere, Finland. A case is understood as "a phenomenon of some sort occurring in a bounded context" (Miles, Huberman, \& Saldaña, 2014, p. 28). We used a longitudinal, qualitative case study approach because of the potential this methodology offers to develop deep understandings through detailed investigation of a unique case in a relevant context (Stake, 1995). We began investigation when Mediapolis was "only an idea" in 2011. In this initial period of establishment and early operations, our research focus was on management challenges and practices for the cluster. We explored the dualities in relation to the levels of integration discussed earlier. The case was relevant to our research question because the cluster's viability depended on success in managing the development of a value network in the context of a media cluster.

On its website, Mediapolis is described as “...a centre for storytelling and digital industries, where interdisciplinary innovations are born" (Mediapolis, 2016). The media cluster is the result of intersecting interests. One set of interests is keyed to Creative Tampere, a regional industrial development plan for the city that was operational in 20062011. Tampere is the main city of the Pirkanmaa region and the 3rd largest city in Finland. It is not a typical international city for a media cluster location, but it is historically important to broadcasting operations and production for the country.

The second set of interests was of the national public service broadcaster, Yleisradio Oy (Yle). Yle's management considered ending operations in Tohloppi, a neighbourhood of Tampere located about seven kilometres west of the city centre. The aim was to save costs 
by consolidating production in Helsinki, where the headquarters and primary production facilities are located. Yle's intention to leave Tohloppi stirred great concern among Tampere city and Pirkanmaa regional authorities, as well as local independent media companies that are content producers for Yle. A solution was needed to satisfy the concerns of these diverse interests. Yle was able to legitimate a continuing presence in Tohloppi without owning the real estate, and financially benefitting from its sale. A crucial factor for the success of this was framing the cluster development project in relation to a new corporate strategic focus on greater "openness", and building public-private partnerships as the best means to achieve innovation in Yle's media content and services. Tohloppi was considered an ideal test bed for operationalising this strategic objective of Yle opening up and increasing collaboration in partnerships. The local authorities believed a media cluster could be economically advantageous for the city and region, and this continues to date. This was reflected in policy, which emphasised developing creative industries and innovations as a means for revitalising the economy. Securing Yle's continuing presence in Tampere was the key objective for the City, which provided a start-up grant of $€ 750,000$ of EU funding to co-finance the initial period of Mediapolis development.

Negotiations with a third partner, started in 2011, were crucial to the start-up of Mediapolis. This third party was Technopolis, an international real estate development company whose core business was leasing real estate. This firm bought the premises from Yle in October 2012. Long-term rental contracts with Yle (20 years) and the Tampere University of Applied Sciences (TAMK, owned by the city of Tampere and in need of new operational premises) were prerequisites for making the deal. After the deal was agreed upon in 2012, Yle vacated approximately 7000 square meters of facility space, however, Yle remains a big renter with an active production and administrative presence.

Technopolis undertook extensive renovation of the premises in 2013 - 2014. During this period, the partners formed an unofficial board comprised of Technopolis (as Chair), Yle, TAMK, Tampere City through Tredea (Tampere Region Economic Development Agency), and an external consultant to handle Mediapolis development. The Board collaborated in developing the vision and aims for Mediapolis. It was widened in 2014 to include Aito Media (founded in 2003 and part of Content Media Group since 2013), which is an independent media production firm located in Tampere and Helsinki. The Mediapolis “campus" launched in autumn 2014, when TAMK and the first private companies moved there. 
In January 2016, a new phase of Mediapolis development began, and a new partner was added: Aito Tehdas, a joint enterprise between Aito Media and a Tampere-based event production company, Akun Tehdas. It operates a new studio and production facility built in Mediapolis in 2015. The partners founded a Co-operative company as a legal entity to manage Mediapolis. This is an effort to solve a range of tensions and problems caused by uncertain management that characterised the formation and early establishment phase. The Yle representative to the board was nominated Chair for this Co-operative. Tampere City considered its role as "an incubator" of the project, and was active in the beginning, but did not need to join the Co-operative.

As a cluster per se, Mediapolis has exceeded expectations. In 2012 when Technopolis bought the premises, the goal was to have 1000 people located at Mediapolis by 2015 (in various roles - as employees, freelancers, entrepreneurs, students, or teachers). This aim was considered ambitious, but the goal has been far surpassed. As of 10 March 2016, a total of 1,888 individual access passes had been activated for Mediapolis. A total of 35 organisations were co-located on the premises, meeting the high end of the projected goal that was set for 2020. In March 2016, only one office was vacant. The first organisations moved to Mediapolis in late 2014 (Yle was already located there), and none had left at the time of this study. Thus, as a spatial agglomeration project, the cluster has been successful.

\section{Methodology}

The first author has close relations with Yle due to her personal history as a previous employee and manager in the company $(1995$ - 2006). She has maintained professional relations with company representatives. Discussions on Yle strategy, leaving Tohloppi, and subsequent plans to establish a media cluster in the premises, awakened her research interest, together with the second author, also a former manager at Yle (1997 - 2007). Owing to previously developed contacts, the first author had comprehensive access to Mediapolis decision-makers, partners and documentation, producing a wealth of qualitative data. Because both authors previously worked as managers for the Mediapolis anchor firm, Yle, but have no current direct or formal ties to the firm, the case offered a rare opportunity to gain access to information that can result in deeper understandings, made more unique with the possibility to conduct research from the start of the project. 
Data collection was conducted in the various stages of Mediapolis development. The first round of interviews was done in March-April 2013, the second in November 2015, and the latest in March 2016. This comprised the main empirical data for analysis and consisted of 18 semi-structured interviews with 15 individuals from 12 organisations involved in Mediapolis. The sample was purposive (Patton, 2015), specifically targeting the core partners responsible for Mediapolis early development and management (the Board and the Co-operative), as well as each of the contracted external expert consultants deeply involved in the project. The sampling approach aligned with the research objective to deepen understanding about value network management in the media cluster. The first round interviewees included representatives with management-level responsibilities from each of the unofficial Board member organisations and an external consultant who was involved in the initial development of the Mediapolis operational model. The second interview round involved three external consultants working on Mediapolis development (in relation to management and operations, communication and marketing), and one Yle representative. The latest interviewees included managerial representative(s) from each of the newly established Co-operative partner organisations, two independent media entrepreneurs located in Mediapolis for widening the perspective on practice, and one representative from Tredu, a Vocational College for the Pirkanmaa region. Tredu is owned by Tampere City and was required to move its media-based education to Mediapolis in autumn 2014.

The first author recruited the participants by email or phone. All but one agreed to participate, and in that instance she was directed to another respondent from the same organisation. The interview questions were collaboratively developed by the two authors in English and translated into Finnish by the first author, who is fluent in both languages. Questions in the first round of interviews focused on thematic issues related to the rationale for Mediapolis for the respondents' respective organisations, especially the vision and aims for the cluster, its management and operational structure, problems or tensions encountered or anticipated, Tohloppi as a location, the role of Tampere city and Pirkanmaa region, Mediapolis financing, and future expectations. The second and third rounds of interviewing focused on the development process, including the management procedures and model, the experienced benefits and successes of being co-located, and potential problems and expectations of Mediapolis partners.

The first author met the interviewees in their personal offices or at Mediapolis, whichever was most convenient for each. The order of questioning varied, being attuned to 
the flow of discussion. Interview length varied from 38 minutes to 1 hour 46 minutes. The average interview length was 1:07. The interviews were conducted in Finnish and digitally recorded. The first author transcribed the first round of interviews, and the rest of the interviews were transcribed by a professional transcribing firm and checked by the first author for accuracy.

Supplementary research materials included Mediapolis documentation and project reports from the start of the project in 2011, frequent informal unrecorded discussions with the Chair of the Mediapolis Co-operative Board (five times between June 2015 and September 2016 to gather background information, check details and follow on-going development), as well as participating in the Mediapolis board meeting on 22 February 2013, a presentation of the Mediapolis management and operational model development by a project consultant in August 2014 (when the EU-funded project was approaching the final reporting stage), and the first author's observations at Mediapolis and participation in the following events and presentations:

- An information event presenting Mediapolis to stakeholders and potential future partners (i.e., tenants) at Technopolis premises on 30 May 2013

- "Knocking down the Tohloppi fences" event that celebrated the opening of the Mediapolis area for visitors on 29 August 2013

- Yle openness happening at Mediapolis on 19 August 2014.

\section{Analysis strategy}

Analysis of the research material explored the Mediapolis development process and the interviewees' interpretations and conclusions about that. Thus, the approach towards the interviews was "factual” (Alastalo \& Åkerman, 2010; Koskinen, Alasuutari, \& Peltonen, 2005). The interviewees were considered expert informants of Mediapolis development. The author relied on the data she collected through the interviews, supporting documentation and participatory observation described above. As typical for qualitative research, the preliminary analysis started during the interviews and continued immediately after each interview meeting, when the author made notes of personal observations (Miles et al., 2014; Patton, 2015).

Before coding, the first author reviewed and read the interview transcripts several times to ensure familiarity with the material. She repeatedly listened to the recorded 
interviews to capture nuances. During this process, she took extensive notes and used those to facilitate coding and analysis of the transcribed interviews. Qualitative thematic coding was used to discover connections and patterns of similarities and differences in the empirical material. This was necessary to build understanding of the structures and themes in relation to the theoretical framework (Miles et al., 2014; Patton, 2015). Atlas.ti software was used for the analysis.

Detailed analysis employed the dualities and integrative levels discussed in the theory section as analytical tools. However, in developing the analysis we realised that strategy and tactics were focused on operational issues. Because Mediapolis is a new cluster, participants have been concentrated on developing practices at the operational level. The issues discussed by respondents with regard to strategic and tactical levels were therefore ultimately focused on operational level needs, problems and ambitions. Thus, we decided to focus the analysis of strategy and tactics on the operational level, instead of treating the latter as a separate focus. This facilitated fresh insights, as shown in the findings and discussed at the end of the article.

The respondents were promised full anonymity. For the analysis and reporting purposes, they were numbered 1-15. In reporting results, we offer no indication of the organisation each respondent represents. However, we can analyse what the partners said in relation to other partners to develop understanding of Mediapolis network relationships. We can also differentiate between public and private/commercial organisations, and between big and small organisations. Preliminary results were summarised in English and the two authors worked together to refine and critically examine the understandings presented next.

\section{FINDINGS}

The Mediapolis case illustrates managerial challenges and tensions in the creation of a media cluster, most of which hinge on the need to become a value network in order to achieve operational goals. Findings are treated as 1) opportunities and limitations for Mediapolis as a strategic integration issue, and 2) influencing and being influenced between Mediapolis partners as a tactical integration issue. Control and release at the operational level of integration are discussed in relation to strategy and tactics, as earlier explained. Quotes illustrate the findings and have been translated from Finnish. 


\section{Strategic integration: Managing the duality between opportunities and limitations}

On the strategic level of integration, Mediapolis is expected to enrich opportunities for growth, entrepreneurial action, employment and innovation in digital Finnish media production. As one respondent described this in 2013,

If we are brave to think big enough there are many kinds of possibilities, as we have talked about with a few of the companies that are planning to locate there.

Respondent 7

In 2013 there were differences of opinion about the cluster strategy, but they were considered minor. Some saw the differences as a potential asset:

This type of project is considered relevant because we collect the different views and hopefully make a reasonable synthesis of them.

Respondent 1

In time, however, a lack of alignment between strategic aims and operational requirements for managing a cluster created tensions. A 2016 comment illustrates:

We have to aim high, that's self-evident. This cannot be regional but has to be national and international, we need to keep the big visions in mind. But to get there, one needs to understand that everything is built on the grassroots level, in day-to-day operations and small things that build the big picture. And these need to be fluent, correctly priced, well accomplished and rightly organised.

Respondent 13

Opportunities for achieving cluster ambitions were constrained by high degrees of uncertainty and lack of operational experience in managing the cluster. This problem persisted for longer than perhaps necessary due to lack of managerial cohesiveness among the partners, each of which was accustomed to managing an independent organisation rather than an interdependent network. The Mediapolis Board benchmarked the Salford cluster in the UK, but soon realised it is not possible to copy a cluster "model". This is because each 
cluster depends so heavily on the contexts, which inscribe the strategy and prescribe the aims, and are keyed to the respective interests of cluster partners.

Strategic level tensions are partly accounted for by variation in priorities across the partners, despite general agreement on long-term aims for the cluster. Differences in priorities were especially noticeable when comparing perspectives from representatives in public service and private commercial firms. The strategic level of integration requires a business model for the cluster, but this was complicated by Yle's non-commercial and notfor-profit charter. Yle is not a business, but it is the main buyer for the business partners in the cluster. Strategic priorities were not aligned. Yle wants to open its production resources for others to utilise - at a price - but those resources are derived from public funding and pricing services requires business logic. Yle has little experience in this, and therefore limited expertise. Opportunities for the cluster as a value network have been constrained by limitations inherent to a core partner - Yle as the anchor of Mediapolis.

For its part, Yle seems uncertain how to operate in the cluster context, indicating their corporate strategic priority of collaborating and greater "openness" is at odds with their strategic position as a unique media operator in the Finnish media system. This has been the source of paralysis that commercial partners find frustrating. As one respondent explained about Yle in 2016,

It is not tuned to a similar timing as the commercial operators where you must react rather quickly and make a decision, which can be good or bad, but above all they have to make a decision. They cannot stay in a state of indecisiveness because the business goes down if no decisions are made, and that is the worst scenario.

Respondent 13

Another respondent exclaimed,

Hey, c'mon, if we want to get something done, we have to make decisions and start doing.

Respondent 14

Thus, by 2015 differences in perspective were no longer seen as strategic opportunities but experienced as operational problems. As described by respondents, 
strategic level aims were not aligned with operational level realities. As one respondent said in 2016,

There is kind of an agreement about the big vision, but not about the concrete steps. The Mediapolis vision is not really relevant for the daily priorities of the partners.

Respondent 6

The focus today is defining Mediapolis at the level of concrete operations, with emphasis on management requirements to achieve cluster ambitions. In short, the focus is on operationalising a value producing network. This is reflected in a remark from one respondent in 2016:

There is a paradox here that since 2011 we have tried to build the operational model, but the truth and practice has shown that it is more useful to just do things and build models afterwards based on the action.

Respondent 11

At the strategic level there was a rational, planned approach to Mediapolis as a real estate development project, but not for the managerial aspect that is a critical success factor at the operational level as a cluster. In the past 18-months, developing the management model and practices has become a top priority, as evident in establishing the Co-operative company as a tool for clarifying roles and responsibilities.

Despite noted problems, it is important to acknowledge enormous contributions from the anchor, Yle, which have been crucial for what Mediapolis has achieved to date. As one respondent said,

Yle's commitment to this has been extremely good, and without it this process would not have moved ahead this way.

Respondent 14

The degree of commitment is affected by external factors that are often crucial in media industries where policy and politics play a powerful role (like the Tampere City and Pirkanmaa Region support) - especially for firms in the public sector, like Yle. 
Yle's situation in Finland was recently re-evaluated by a parliamentary committee. Commercial media operators have been loudly questioning Yle's position in the Finnish media market, especially in web-based content and services. This renders Yle an unpredictable anchor. Given its comparative size and importance as a buyer in this media market, it is likely the irreplaceable client firm for Mediapolis success. Thus, on the one hand Yle's corporate strategy continues to emphasise openness and partnerships, which bodes well for developing the cluster as a value network. On the other hand, the political pressures and potential regulatory demands typical for public service media may hamper the development of Mediapolis as a value network. As one respondent observed,

Yle as a partner is so big and so unpredictable that if your operations would only depend on Yle, your company might fall or succeed. [So] it's totally coincidental.

Respondent 10

\section{Tactical integration: Managing the duality between influencing and being influenced}

As stated, Yle has a role of central importance as the client-firm anchoring the Mediapolis cluster. A critical success factor for Yle's participation in the Mediapolis development is the capability of the cluster to offer possibilities for Yle to realise its corporate strategic intentions of achieving greater openness and building partnerships. Problems noted in discussion of strategic level integration were also manifested at the tactical level, where the tensions hinge on the duality of each partner being simultaneously an influence and influenced. Mediapolis partners considered potential collaboration with Yle as a crucial influence and success factor for both the cluster development and their own business opportunities. However, at the same time they feared that Yle's strategic objective of opening up and developing partnerships might not actualize in practical terms, as one respondent observed in 2013 ,

The most essential point is that Yle really opens up rather than fancy talk about that.

Respondent 8

After the EU-funded phase ended in January 2015, the Mediapolis project was at a crossroads. The initial "meeting of the minds" and respective commitments that were agreed 
at the strategic level early on were waning. The flames of enthusiasm burned much lower. The decisive challenge has been in building the management model for operations as a value network, rather than a disparate assortment of co-located organisations. In other words, the cluster was not sufficient to realise the partners' ambitions for its creation. In November 2015, the main partners held a pivotal meeting in which the situation was frankly discussed and the decision was taken to found a Co-operative as the best option for the Mediapolis "business model". At the time of this writing, the Co-operative's functions are not yet firmly defined and there are varying perspectives between partners regarding its future role, but this is clearly a step forward in the development of cluster management.

Since 2013, it had become increasingly clear to the partners that inter-organisational relationships must be managed, and that it is something of shared importance, as value network theory suggests. Being co-located as a cluster has not met expectations and produced success in relation to Mediapolis aims to become a network and a seedbed for innovations. Further, Mediapolis is not well known internationally and is not a benchmark, due to slow development of global pipelines. The cluster must become more than a successful real estate redevelopment project for the partners to realise sufficient value for the costs of agglomeration. There was growing recognition among the partners of the need for managed routines, processes and roles to facilitate collaborative practice. This was described by a respondent in the second interview round in 2015 :

The unsolved, shared area of responsibilities has been too big and unclear, and it has hindered the development of concrete small things. Many partners have wondered what is done here because nothing happens ... It's a cruel truth in the background that when there are no process functions or supporting machinery that could create co-operation or new business. This exists on paper. But you cannot build them only on paper.

Respondent 5

The partners consider the Co-operative a solution to facilitate making advances in content innovation and production. As noted in the literature review, there are frequently complications in network relationships because each node is relatively independent, but at the same time must be interdependent - each node is an influence and is also influenced. The weakest link in the Mediapolis chain of interdependent relationships was the lack of a productive partnership at the operational level, including the roles and responsibilities, which 
caused serious difficulties at the tactical level. What Yle did and did not do was a significant influence on the cluster as a network, and at the same time, the growing realisation that the cluster was not working influenced Yle to support the Co-operative solution.

The interests of organisations as such matter greatly, and this is complicated because, as a respondent explained,

... we are open but cannot be [that] in certain issues... we play towards the same goal but nonetheless everyone has their own games in the background with their own objectives.

Respondent 11

The duality of being an influence and being influenced will persist and is therefore a crucial management need for the cluster. At issue is the degree to which the influence dynamic is mutually beneficial or contributes to shared failure - a virtuous circle or vicious spiral. This highlights the importance of the network within and beyond the cluster.

The expectations and needs of small independent entrepreneurs and the big operators differ significantly. As one of the "small" interviewees said,

I don't expect Mediapolis to create anything because I have to create everything myself ... I think it is unthinkable that I would come here and expect them to do or bring something for me. How can they know what I need because I myself do not know?

Respondent 4

This implies the need to recognise not only mutual interests and influences, but also differences between organisations. The weakest node affects the network as a whole and this is especially problematic if weaknesses are evident in the client-firm that anchors the cluster. Large public operators have ample resources to enable their employees to spend time on Mediapolis development, while small companies (not to mention freelancers) find this difficult or impossible due to opportunity costs - i.e. lost time in revenue-generating work. Their motivation to participate in cluster development would require either external funding or high (and often immediate) prospects for new business creation. Thus, the capacity to influence is not easily balanced. But if the 'smalls' as a group are not able to exert sufficient influence on the network to ensure a reasonable livelihood, they might have considerable 
influence by pulling out of the project - which would certainly pose an existential dilemma for the 'bigs'.

The necessary next step is to operationalise the cluster as a value-producing network. This is demanding because of variation in motivations among the partners. As one respondent explained,

The root reason is a positive problem that no one's business is directly dependent on the cooperation. This makes the motivational level and drivers rather feeble. It is already a success because it is up and running, works and is full of people. It's a won case. [But] now when we try to move from this basic level to the ideal level that is pursued, the motivations are not strong - there are no imperative reasons for action.

Respondent 5

This points to problems caused by a lack of leadership, which is a cluster management problem. The operational duality between control and release highlights the problem of one firm exerting too much control over a network, thereby threatening to destroy its potential to create unique value as a network. But in the case of Mediapolis, we see a problem is caused by the lack of sufficient control (too much release) in managing the cluster. The degrees of independence are too high for the cluster to realise sufficient value from co-location because there is insufficient networked collaboration among the partners. They have been co-located, but not co-ordinated; here is density, but not enough intensity; there is high potential for connectivity, but not enough conductivity in practice.

\section{DISCUSSION}

Although industry clusters and value networks have separately been the focus of considerable research interest, the possible gains from combining these theoretical approaches with clear links to practice has yet to be explored. Linking them in this project has proven useful for deepening understanding of how the development of both depends heavily on the quality of management policy and practice. We have analysed the Mediapolis case on that basis in the context of creative industries with an emphasis on three dualities (Håkansson \& Ford, 2002) at two levels (strategic and tactical) of needed integration with a focus on their implications for the third level (operational) (see Coughlan et al., 2003). 
Based on our analysis, we note that managerial challenges in establishing and developing Mediapolis as a cluster are typical in the media industry context (cf. Karlsson \& Picard, 2011). What is also evident from our case study is a co-related set of challenges keyed to difficulties in realising sufficient value from co-location in a cluster alone, which points to the need to build a value network across and beyond cluster boundaries. In our empirical case, the cluster and network for Mediapolis overlap and are clearly interdependent. A key finding of our study was that network relationships were the most essential factor for producing value in the Mediapolis cluster. Achieving this depends on routine collaboration, which in our case was not happening sufficiently despite the density of the Mediapolis cluster as a spatial agglomeration of firms (see Picard, 2008). Thus, the density of companies in a cluster is no substitute for the intensity of interactions between them, suggesting that mere co-location does not guarantee benefits expected from the cluster participation (cf. Achtenhagen \& Picard, 2011). Our findings demonstrate that networked interactions in the cluster context merit close consideration, and that linking the theories of clusters and value networks provides a useful theoretical framework to do so. We expand further on this point in the next section.

\section{Theoretical contributions}

For its part, a network perspective on cluster management is helpful because the interdependencies are complex and diverse (Duysters et al., 1999; Peppard \& Rylander, 2006). Differences create tension, disagreement and conflict. This can be healthy when the issues are substantively important and resolved amicably, or can cause dysfunctional problems if not handled well. In the end, this is a job for managers. If the cluster is not focused on creating value in and through the substance of what participants are doing, then it cannot be much more than a real estate development project. Once that is achieved, however successfully for the real estate owner, it has limited possibilities for adding value to justify the cost to participants for co-location. The media cluster is a platform, like Mediapolis is expected to become, for sharing knowledge, developing innovation, and creating value that is shared. Thus, "the exchange is what is really important" (Allee, 2000, p. 38). Our analysis of the Mediapolis case extends theory on industry clusters by demonstrating that effective cluster management conforms to the criteria associated with the value creation logic and development of a value network across and beyond cluster boundaries. Such management is 
dynamic, ongoing, and strategically driven by the goal of shared value creation. Moreover, value networks purposefully configure interdependent relationships between organisations that collaboratively aim at creating value. Put another way, the cluster concept of co-location falls short of solving the need for actual interactions focused on achieving intended results; bringing theory on value networks to bear on this question, provides novel theoretical ground to advance research on industry cluster management.

The potential for value creation in collaborative value networks is based on interaction at strategic, tactical and operational levels, as suggested by previous research (Coughlan et al., 2003; Kanter, 1994). However, our analysis found that treating these levels separately, although conceptually useful, does not untangle the problems with practice, and we can conclude that everything ultimately comes down to operational management. We thus extend theory relating to the role of strategy in cluster success by showing that strategic level integration does not guarantee cluster success as a value network, even when there is general agreement on the vision among cluster partners. Issues highlighted by our respondents regarding strategic and tactical level dualities were linked to frustrations and opportunities in operational terms. At the operational level, the cluster was not integrated, and thus the management challenge was about the relative imbalance and duality between control and release. Accordingly, our findings extend value network theory by showing that simultaneous integration of the strategic and tactical levels through operational management are essential conditions for success.

Based on our analysis, and as illustrated in the empirical quotes in the findings section of this article, integration at the strategic level has been reasonably successful in Mediapolis. The main partners are "on the same page" regarding the vision and general ambitions for the cluster. The opportunities that should be opened by co-location in theory are limited, however, by lack of integration at the operational level. This is a key managerial challenge that hinges on developing the cluster as a network to realise sufficient value from its operation to justify the costs involved in agglomeration.

\section{Limitations and opportunities for future research}

As with all studies, our study has important limitations. We concentrate on a single case study, which means the findings may not be fully generalizable. Triangulation between the authors in relation to the original data was constrained by language issues, leading to 
potential researcher bias. However, multiple interviews with multiple interviewees as well as multiple sources of empirical research material support the trustworthiness of the results. We have been able to follow the case from the start of Mediapolis development, which is not only a rare opportunity to achieve a longitudinal case study over the cluster's lifecycle, but also enabled us to obtain respondents' reactions to our findings and correct our understandings as the research developed along with the cluster.

The Mediapolis project reached its goals as a real estate development project well ahead of schedule, and its goals for populating the cluster were admirably exceeded. This may be surprising in the light of cluster theory because Tampere has comparative liabilities. It is not a major international city or urban area that is typical for creative cluster locations (Davis et al., 2009), and Tohloppi is on Tampere's periphery. The potential for local buzz and global pipelines is not as great as for many media clusters (Bathelt, 2005; Bathelt et al., 2004). Mediapolis is therefore an interesting case in the light of earlier media cluster research (e.g. Karlsson \& Picard, 2011) and merits further investigation in relation to the location aspect.

Further research on Mediapolis is needed about the two other levels of integration proposed by Coughlan et al. (2003), i.e. the interpersonal and the cultural levels. On the face of it, the interpersonal advantages to be gained from clustering do not inherently result in the realisation of sufficient value in operational practice, without management policies and practices to capitalise on that. Regarding the latter, an uncertain period of time is always required to accumulate the experiences that are necessary to build trust, develop routines, embed rituals and tacit knowledge that are prerequisites for an inter-organisational culture. That is to say, a cluster culture that is shared enough and durable enough to ensure sustainability.

In future research, it would be useful to dig deeper into the nature of the suggested integration levels: strategic, tactical, operational, interpersonal, and cultural (see Coughlan et al., 2003). Our analysis demonstrates the utility of linking strategic and tactical levels with a focus on the operational level. We suspect more insights could be generated by working backwards from the operational to the other two levels as the cluster becomes firmly established. At some point, operations may become misaligned with strategy, for example. This is likely the period when focusing on the cultural level would also become fruitful. On the basis of our analysis, the Mediapolis cluster's success depends on the degree to which the levels are not treated as separate layers, but as intersecting arenas of management 
practice. Thus, the different levels in general may be more usefully conceptualised as the complex interplay between interdependent arenas of management activity and context in further research.

\section{CONCLUDING REMARKS}

The Mediapolis case demonstrates why it is crucial to consider the types of integration at different levels as a dynamic structure. This is a pivotal issue for the management of a media cluster as a value network. If strategic integration is incoherent, it is difficult to develop practical solutions that ensure tactical and operational integration. If operational integration is not accomplished, the strategy is likely to be untethered and the tactics confused and at cross-purposes. In this view, building a value network is as important for mutual success as cluster development. That is why it seems useful to integrate theories of industrial clusters and value networks. Doing so has potential to advance theory and improve managerial understandings, and thereby practices. We conclude that functioning, effective collaboration is possible without a cluster, but a cluster cannot be effective without a functioning value network.

In future research, we want to compare the case of Mediapolis, which is a brownstone project, with Malmö in Sweden and Salford (near Manchester) in the UK, which are greenfield projects. Each of these cluster configurations represents a different approach to developing a media cluster and comparative research should be fruitful for coming better to grips with the expectedly decisive role of context. This would contribute to advancing management theory and practice in relation to clusters, especially those that are not situated in major international cities like creative cluster theory generally suggests. This seems especially important given the growth of interest to develop clusters in regions suffering economic decline as a presumed means for facilitating economic revitalisation.

To conclude, we concur with Duysters et al. (1999, p. 199) that "the real strategic potential of alliances can only be realised when the network as a whole is managed". Development seems to be always hostage to circumstances, which emphasises the importance of considering contextual features in developing both management theory and practice in relation to value networks in creative industry clusters. 


\section{References}

Achtenhagen, L. \& Picard, R. (2011). Media clusters: Development paths and core issues. In C. Karlsson \& R.G. Picard (Eds.), Media clusters: Spatial agglomeration and content capabilities (pp. 44-71). Cheltenham, UK: Edward Elgar.

Achtenhagen, L. \& Picard, R. (2014). Challenges and success factors in media cluster development: A review of contemporary knowledge. In C. Karlsson, B. Johansson, \& R.R. Stough (Eds.). Agglomeration, clusters and entrepreneurship. Studies in regional economic development (pp. 221-251). Cheltenham, UK: Edward Elgar.

Achtenhagen, L., \& Raviola, E. (2009). Balancing tensions during convergence: Duality management in a newspaper company. International Journal on Media Management, 11, 32$\underline{41 .}$

Alastalo, M., \& Åkerman, M. (2010). Asiantuntijahaastattelun analyysi: Faktojen jäljillä. In J. Ruusuvuori, P. Nikander, \& M. Hyvärinen (Eds.), Haastattelun analyysi (pp. 372-392). Tampere: Vastapaino.

Allee, V. (2000). Reconfiguring the value network. Journal of Business Strategy, 21(4), 3639 .

Allee, V. (2003). The future of knowledge: Increasing prosperity through value networks. Amsterdam: Butterworth-Heinemann.

Allee, V. (2009). Value-creating networks: Organizational issues and challenges. The Learning Organization, 16, 427-442.

Allee, V., \& Taug, J. (2006). Collaboration, innovation, and value creation in a global telecom. The Learning Organization, 13, 569-578.

Bathelt, H. (2005). Cluster relations in the media industry: Exploring the 'distanced neighbor' paradox in Leipzig. Regional Studies, 39, 105-127.

Bathelt, H., Malmberg, A., \& Maskell, P. (2004). Clusters and knowledge: Local buzz, global pipelines and the process of knowledge creation. Progress in Human Geography, 28, 31-56.

Benkler, Y. (2006). The wealth of networks: How social production transforms markets and freedom. New Haven, CT: Yale University Press.

Bilton, C. (2007) Management and creativity: From creative industries to creative management. Malden, MA: Blackwell Publishing.

Castells, M. (2010). The rise of the network society 2nd ed. Chichester, UK: WileyBlackwell Ltd.

Christensen, C.M. (1997). The innovator's dilemma: When new technologies cause great firms to fail. Boston, MA: Harvard Business School Press. 
Christensen, C.M. (2006). The ongoing process of building a theory of disruption. The Journal of Product Innovation Management, 23, 39-55.

Christensen, C.M., Raynor, M., \& McDonald, R. (2015). What is disruptive innovation? Harvard Business Review, 93(12), 44-53.

Connell, J., Kriz., A., \& Thorpe, M. (2014). Industry clusters: An antidote for knowledge sharing and collaborative innovation? Journal of Knowledge Management, 18, 137-151.

Clegg, S., Vieira de Cunha, J., \& Cunha, M.P. (2002). Management paradoxes: A relational view. Human Relations, 55, 483-503.

Coughlan, P., Coghlan, D., Lombard, F., Brennan, L., McNichols, T., \& Nolan, R. (2003). Managing collaborative relationships in a period of discontinuity. International Journal of Operations \& Production Management, 23, 1246-1259.

Danneels, E. (2004). Disruptive technology reconsidered: A critique and research agenda. Journal of Product Innovation Management, 21, 246-258.

Davis, C.H., Creutzberg, T., \& Arthurs, D. (2009). Applying an innovation cluster framework to a creative industry: The case of a screen-based media in Ontario. Innovation: management, policy \& practice, 11, 201-214.

De Rose, L.J. (1994). The value network. Integrating the five critical processes that create customer satisfaction. NY: Amacom.

Díez-Vial, I., \& Fernández-Olmos, M. (2013). Internal resources, local externalities and export performance: An application in the Iberian ham cluster. Journal of Management \& Organization, 19, 478-497.

Doyle, G. (2013). Understanding media economics $2^{\mathrm{n}}{ }^{\mathrm{n}}$ nd ed. London: SAGE Publications.

Drucker, P. (2007). The essential Drucker. Amsterdam: Elsevier BH.

Duysters, G., de Man, A.P., \& Wildeman, L. (1999). A network approach to alliance management. European Management Journal, 17, 182-187.

Dwyer, P. (2016). Managing creativity in media organisations. In G.F. Lowe \& C. Brown (Eds.), Managing media firms and industries: What's so special about media management? (pp. 343-366). Heidelberg, Germany: Springer-Verlag.

European Commission (2016). Horizon 2020. The EU Framework Programme for Research and Innovation, accessed at https://ec.europa.eu/programmes/horizon2020/en/what-horizon2020 on 26 October 2016.

Florida, R. (2012). The Rise of the Creative Class Revisited. NY: Basic Books. 
Galvin, P. (2014). A new vision for the Journal of Management \& Organization: The role of context. Journal of Management \& Organization, 20, 1-5.

Ghezzi, A. (2013). Revising business strategy under discontinuity. Management Decision, 51,1326-1358.

Hitters, E. \& Richards, G. (2002). The creation and management of cultural clusters. Creativity and Innovation Management, 11, 234-247.

Härtel, C.E.J. (2014). Advancing organizational behavior through context considerations. Journal of Management \& Organization, 20, 415-416.

Härtel, C.E.J., \& O'Connor, J.M. (2014). Contextualizing research: Putting context back into organizational behavior research. Journal of Management \& Organization, 20, 417-422.

Huggins, R. (2008). The evolution of knowledge clusters: Progress and policy. Economic Development Quarterly, 22, 277-289.

Håkansson, H. \& Ford, D. (2002). How should companies interact in business networks? Journal of Business Research, 55, 133-139.

Jenkins, H. (2008) Convergence culture: Where old and new media collide. NY: New York University Press.

Jörgensen, J.H., Bergenholtz, C., Goduscheit, R.C., \& Rasmussen, E.S. (2011). Managing inter-firm collaboration in the fuzzy front-end: Structure as a two-edged sword. International Journal of Innovation Management, 15(1), 145-163.

Kanter, R.M. (1994). Collaborative advantage: The art of Alliances. Harvard Business Review, 72(4), 96-108.

Karlsson, C., \& Picard, R.G. (2011). Media clusters: what makes them unique? In C. Karlsson \& R.G. Picard (Eds.), Media clusters: Spatial agglomeration and content capabilities (pp. 3-29). Cheltenham, UK: Edward Elgar.

Koskinen, I., Alasuutari, P., \& Peltonen, T. (2005). Laadulliset menetelmät kauppatieteissä. Tampere: Vastapaino.

Krätke, S., \& Taylor, P.J. (2004). A world geography of global media cities. European Planning Studies, 12, 459-477.

Küng, L., Picard, R.G., \& Towse, R. (2008). The Internet and the Mass Media. London: SAGE Publications.

Lee, Y-M., \& Yan, C. (2014). The relationships among network ties, organizational agility, and organizational performance: A study of the flat glass industry in Taiwan. Journal of Management \& Organization, 20, 206-226. 
Lewis, M. (2000). Exploring paradox: Toward a more comprehensive guide. The Academy of Management Review, 25, 760-776.

Lowe, G.F. (2016). PSM in the $21^{\text {st }}$ century: What value and which values? Geneva, Switzerland: European Broadcasting Union.

Lowe, G.F., \& Brown, C. (Eds.) (2015). Managing media firms and industries: What's so special about media management? Heidelberg, Germany: Springer-Verlag.

Lowe, G.F., \& Stavitsky, A.G. (2016). Ensuring public service news provision in the era of networked communications. The International Communication Gazette. Advance online publication. doi: 10.1177/1748048516632163

Lowe, G.F., \& Yamamoto, N. (Eds.) (2016). Crossing borders and boundaries in public service media, RIPE@2015. Göteborg, Sweden: NORDICOM.

Mediapolis (2016). Accessed at http://mediapolis.fi/en/ on April 7, 2016.

Miles, M.B, Huberman, A.M., \& Saldaña, J. (2014). Qualitative data analysis. A methods sourcebook 3rd ed. Thousand Oaks, CA: Sage Publications.

Noam, E. (2009). Media ownership and concentration in America. USA: OUP USA.

Patton, M.Q. (2015). Qualitative research \& evaluation methods $4^{\text {th }}$ ed. Sage, Los Angeles.

Peppard, J., \& Rylander, A. (2006). From value chain to value network: Insights for mobile operators. European Management Journal, 24, 128-141.

Picard, R.G. (2008). Media clusters: Local agglomeration in an industry developing virtual clusters. Jönköping International Business School: Working Paper Series No. 2008-3.

Pil, F.K., \& Holweg, M. (2006). Evolving from value chain to value grid. MIT Sloan Management Review, 47(4), 72-80.

Poole, M.S., \& van de Ven, A.H. (1989). Using paradox to build management and organization theories. The Academy of Management Review, 14, 562-578.

Porter, M.E. (1985). Competitive advantage: Creating and sustaining superior performance. NY: Free Press.

Porter, M.E. (1998). Clusters and the new economics of competition. Harvard Business Review, 76(6), 77-90.

Porter, M.E. (2000). Location, competition, and economic development: Local clusters in a global economy. Economic Development Quarterly, 14, 15-34.

Powell, W.W., Koput, K.W., \& Smith-Doerr, L. (1996). Interorganizational collaboration and the locus of innovation: Networks of learning in biotechnology. Administrative Science Quarterly, 41, 116-145. 
Riemer, K. \& Johnston, R.B. (2013). Digital Disruption, accessed at https://byresearch.wordpress.com/2013/03/07/digital-disruption/ on 26 October 2016.

Ripollés, M., \& Blesa, A. (2016). Development of interfirm network management activities: The impact of industry, firm age and size. Journal of Management and Organization, 22, 186-204.

Ritter, T., Wilkinson, I.F., \& Johnston, W.J. (2004). Managing in complex business networks. Industrial Marketing Management, 33, 175-183.

Smith, W.K. \& Lewis, M. (2011). Toward a theory of paradox: A dynamic equilibrium model of organizing. Academy of Management Review, 36, 381-403.

Stake, R.E. (1995). The Art of Case Study Research. Thousand Oaks, CA: Sage.

Sutherland, F., \& Smith, A.CT. (2011). Duality theory and the management of the changestability paradox. Journal of Management \& Organization, 17, 534-547. 